\title{
DIREITO FUNDAMENTAL DA DEFESA DO CONSUMIDOR E A FALTA DE INFORMAÇÕES ADEQUADAS NOS RÓTULOS DOS ALIMENTOS SOB A PERSPECTIVA DA PROTEÇÃO À SAÚDE
}

\author{
FUNDAMENTAL LAW OF CONSUMER \\ PROTECTION AND THE LACK OF ADEQUATE \\ INFORMATION ON FOOD LABELING FROM \\ THE PERSPECTIVE OF HEALTH PROTECTION
}

\section{Bruna Camile Burgardt ${ }^{1}$}

Resumo: O presente artigo aborda a importância do direito do consumidor como parte dos direitos e das garantias fundamentais previstos na Constituição Federal de 1988. Elenca-se o reconhecimento necessário desse direito na sociedade de consumo por intermédio do ordenamento consumerista e suas disposições de norma pública e interesse social, que priorizam a preservação da saúde dos consumidores e a aplica- bilidade de seus direitos básicos. Nessa concepção, diante do tema selecionado, analisa-se a efetivação de fato dos direitos básicos e dos princípios constituídos no Código de Defesa do Consumidor, Lei n. 8.078/1990, perante as relações de consumo. Sob o aspecto da preservação da saúde do consumidor, visa-se à necessidade do fornecimento de alimentos que possuam informações adequadas em sua rotulagem, pois o

1 Bacharel em Direito pelo Centro Universitário Católica de Santa Catarina. Estudante de pós-graduação em Direito Público pela Universidade do Vale do Itajaí (Univali) e estudante da Escola Superior da Magistratura do Estado de Santa Catarina (Esmesc). https://orcid.org/0000-0002-7070-9504. E-mail: brunac.burgardt@gmail.com 
não fornecimento de informações adequadas nas rotulagens dos alimentos pode ocasionar riscos, danos e perigo aos consumidores. Por meio dos rótulos alimentares, pode-se respeitar e aplicar os direitos básicos dos consumidores, como o da informação adequada e da preservação da saúde, garantindo, assim, proteção e um consumo consciente. A informação adequada e os rótulos alimentares se relacionam entre si, pois os consumidores compreendendo e recebendo informações adequadas sobre os alimentos podem optar com discernimento pelo consumo e, dessa forma, proporcionar-se-ia mais efetividade para as disposições jurídicas acerca dos direitos e dos princípios básicos presentes no Código de Defesa do Consumidor.

Palavras-chave: Direito do consumidor. Direito fundamental. Informação adequada nos rótulos dos alimentos. Preservação da saúde do consumidor.

Abstract: This paper addresses the importance of consumer rights as part of the fundamental rights provided for in the Federal Constitution of 1988. The recognition of this right in the consumer society is listed through the consumerist order and its provisions of public norm and social interest, which prioritize the preservation of consumers' health and the applicability of their basic rights. In this conception, in view of the selected theme, the actual implementation of basic rights and constituted principles in the Consumer Protection Code, Law 8.078/1990, in relation to consumer relations is analyzed. Under the aspect of preserving consumer health, it is necessary to provide adequate information on food labels, as the lack of adequate information on food labels can cause risks, damage, and danger to consumers. Through food labels, basic consumer rights such as adequate information and health preservation can be respected and applied, thus ensuring protection and conscious consumption. Adequate information and food labels, therefore, are related to each other, as the understanding of consumers and receiving adequate information about food can discern with consumption, where in this way, benefits would be provided for the legal provisions regarding basic rights and principles contained in the Consumer Protection Code.

Keywords: Consumer law. Fundamental right. Adequate information on food labels. Preserving consumer health. 


\section{INTRODUÇÃO}

A defesa do consumidor posta ao ordenamento jurídico brasileiro está evidenciada como parte dos direitos e das garantias fundamentais do art. $5^{\circ}$, inciso XXXII, da Constituição Federal de 1988. Nesse sentido, os fornecedores de produtos e serviços devem garantir a proteção posta pelo ordenamento constitucional juntamente em observância às regras, aos direitos e aos princípios básicos estabelecidos na ordem jurídica do consumidor instituída pela Lei n. 8.078/1990.

Por essa perspectiva, o Código de Defesa do Consumidor, conhecido pela sigla CDC, prevê o princípio e o direito da informação adequada em seu art. $6^{\circ}$, inciso III, no qual está posto que é direito básico do consumidor ter disponibilizado para si informações adequadas sobre os produtos e os serviços. A transmissão de informações se dá no caso dos alimentos pela rotulagem. Assim, diante da ausência de informações compreensíveis e necessárias nos rótulos dos alimentos postos no mercado de consumo, foi importante destacar a defesa do consumidor como um direito fundamental.

Os alimentos são produtos indispensáveis para a sobrevivência, por esse motivo estão ligados com a preservação da saúde e os direitos fundamentais dos consumidores. Rótulos alimentares que não proporcionam todas as informações precisas para que haja um consumo consciente não respeitam os direitos básicos do CDC. À vista disso, com apresentação inadequada dos rótulos dos alimentos no mercado de consumo, viola-se a regra do art. $6^{\circ}$, inciso III, que dispõe sobre o princípio e o direito básico da informação adequada.

Para que haja a preservação da saúde do consumidor e a efetivação dos direitos básicos por meio de uma alimentação consciente, destacou-se a necessidade e a importância da implementação de um modelo que possua informações adequadas e 
de fácil discernimento nos rótulos dos alimentos postos no mercado de consumo, levando-se em consideração às disposições do CDC norma de ordem pública e de interesse social que visa à realização da Política Nacional das Relações de Consumo.

\section{DIREITO DO CONSUMIDOR COMO DIREITO FUNDAMENTAL E A SUA IMPORTÂNCIA}

Os direitos e as garantias fundamentais são disposições especiais que necessitam de observância obrigatória e servem como base de todo o ordenamento jurídico brasileiro. Previstos na Constituição Federal de 1988, encontra-se, juntamente com esses direitos e as garantias fundamentais, a defesa do consumidor presente no art. $5^{\circ}$ e inciso XXXII do mandamento. Logo, a imposição da referida normativa constitucional foi de extrema importância, pois reconheceu o homem como sujeito consumidor perante as práticas de consumo e se tornou referência de interpretação e aplicabilidade por todas as regras jurídicas brasileiras que agregam essa área do direito (EFING, 2010).

Por ser fundamental, entende-se que a defesa do consumidor dispõe de indispensabilidade, pois existe uma "sociedade de consumo" em que todos se satisfazem e sobrevivem mediante a aquisição de produtos e serviços. Assim, o direito do consumidor reconhecido na esfera constitucional também é decorrente dos conflitos constantes nas relações de consumo, ou seja, nas relações entre os fornecedores e os consumidores. Por esse motivo, requer-se equilíbrio e proteção da necessidade de consumir e, principalmente, o reconhecimento do sujeito consumidor como parte mais vulnerável da relação de consumo (MIRAGEM, 2014).

Em resumo, é de suma importância no sistema constitucional brasileiro, um direito estar incluído no rol dos direitos fundamentais e expresso em norma (não 
apenas implícito) na Constituição, como um direito e garantia individual. A defesa do consumidor é um direito e garantia individual no Brasil (art. 5 XXXII da $\mathrm{CF} / 1988$ ), é um direito fundamental (direito humano de nova geração ou dimensão positivado na Constituição) (BENJAMIN; MARQUES; BESSA, 2014, p. 36).

Além de tratar do direito do consumidor entre os direitos e as garantias fundamentais como já mencionado no art. $5^{\circ} \mathrm{e}$ inciso XXXII, o ordenamento constitucional instituiu também $\mathrm{o}$ art. 170, inciso $\mathrm{V}$, perante o capítulo dos fundamentos da ordem econômica, entre os quais se encontra o da defesa do consumidor juntamente com um conjunto de normas e princípios que devem ser observados e cumpridos para se assegurar a devida ordem econômica constitucional em face do sujeito consumidor (EFING, 2010).

A Magna Carta incluiu a defesa do consumidor no plano da política constitucional; essa aparece no texto maior, entre os direitos e deveres individuais e coletivos (art. $5^{\circ}$ XXXII CF/1988), estando também elevada à categoria de princípio geral da atividade econômica (art. 170, V, $\mathrm{CF} / 1988$ ) e justaposta aos princípios basilares do modelo político/econômico brasileiro, como o da soberania nacional, da propriedade privada e da livre concorrência (DELFINO, 2003, p. 2).

Com a incrementação da defesa do consumidor perante a normativa da Constituição Federal de 1988 como direito e princípio fundamental, organizou-se as práticas dessa área do direito em todos os seus sentidos jurídicos. Assim, houve a necessidade da criação de uma série de direitos subjetivos e obrigações necessárias para se poder respeitar e realizar tais direitos, diante os quais o Estado não obteria dificuldade para arbitrar, via legislativa ou judicial, os conflitos e as ilicitudes frente às práticas abusivas constatadas nas relações de consumo (MIRAGEM, 2014). 
Tendo-se a intenção de se efetivar a defesa do consumidor posta ao ordenamento jurídico constitucional brasileiro, juntamente para impossibilitar e penalizar as irregularidades evidenciadas nas relações de consumo, foi sistematizado o Código de Defesa do Consumidor, reconhecido como CDC, Lei n. 8078/90, o qual foi concebido havendo a grande premência de se ter um meio normativo preciso e adequado para se proteger e garantir de forma especial a defesa para os sujeitos consumidores:

De fato, a Constituição, ao cuidar dos Direitos e Garantias Fundamentais, estabelece, no inc. XXXII do art. $5^{\circ}$, que "o Estado promoverá, na forma da lei, a defesa do consumidor". O legislador maior, entretanto, entendeu que não bastava. Assim, mais adiante, no art. 48 do Ato das Disposições Constitucionais Transitórias, determina que o "Congresso Nacional, dentro de cento e vinte dias da promulgação da Constituição, elaborará Código de Defesa do Consumidor" (GRINOVER et al., 2011, p. 6).

O CDC, convencionado pela Lei n. 8.078/1990, teve sua instituição primordial por intermédio do mandamento constitucional, pois ganhou sua denominação advinda do art. 48 das Disposições Constitucionais Transitórias (BENJAMIN; MARQUES; BESSA, 2014). Assim, por meio da interpretação normativa de valores fundamentais, criou-se o direito do consumidor, um direito privado brasileiro com garantia constitucional em que a proteção ao sujeito consumidor é de extrema importância, tendo em vista que a Constituição Federal de 1988 é o ápice e o guia de todo o ordenamento jurídico.

\section{SISTEMATIZAÇÃO DO CÓDIGO DE DEFESA DO CONSUMIDOR}

Para Delfino (2003), as mudanças sociais de cada época foram as que determinaram a defesa do consumidor interpos- 
ta na Constituição Federal de 1988 e foram as que motivaram a criação do ordenamento consumerista perante a legislação brasileira. Tutelou-se as relações jurídicas de consumo para se ter uma realidade social mais justa e igualitária entre os consumidores e os fornecedores dos produtos e dos serviços. Nesse sentido, o CDC teve a sua estipulação abrangendo o caráter de uma norma taxativa e imperativa de direitos e obrigações a serem respeitadas por todos os sujeitos que participam das relações de consumo.

A importância do CDC é inquestionável, tendo sido sua origem percebida de forma mais aparente a partir do século XX no qual o modelo capitalista consumista se fortalece e assume proporções globais. Percebeu-se que a busca pelo capital e a tradição do consumo eram imperiosos e que as relações dentro desse sistema, ainda que díspares, destacavam-se entre as demais relações juridicamente tuteladas (EFING, 2010, p. 33).

O CDC possui, em sua estruturação, o caráter de ordem pública manifesto em seu art. $1^{\circ}$. Trata-se da realização do direito fundamental do consumidor posto pelo ordenamento constitucional (MIRAGEM, 2014).

Normas de ordem pública, também chamadas de coercitivas, imperativas, taxativas ou cogentes, são aquelas que impõem ou proíbem de maneira categórica. Nader conceitua tais normas como aquelas que obrigam independentemente da vontade das partes, isso por resguardar os interesses fundamentais da sociedade (DELFINO, 2003, p. 3).

Segundo Netto (2014), normas de ordem pública cogentes são normas que não toleram, de qualquer maneira, renúncia pelos sujeitos das relações de consumo. Normas em relação às quais são invalidados contratos ou acordos que busquem afastar a sua incidência. Dessa forma, o art. $1^{\circ}$ do ordenamento consumerista, 
ao informar que são estabelecidas normas de ordem pública e interesse social, deixa claro que são de características obrigatórias e não admitem serem afastadas por vontade dos consumidores ou dos fornecedores para resolução de conflitos e, consequentemente, para o fornecimento dos produtos e dos serviços.

Foi preciso o disposto no art. $1^{\circ}$ para conceder melhor eficiência ao CDC, pois, caso contrário, a sua normativa poderia ser ignorada e não respeitada pelos fornecedores durante a prática das relações de consumo. No mesmo sentido, para se abranger uma melhor efetividade ao direito do consumidor com a interposição de instrumentos necessários e hábeis para o acesso à justiça, foi especificado na norma consumerista $o$ "interesse social", que teve por objetivo resgatar a coletividade dos sujeitos consumidores sob o aspecto da atuação do poder econômico (DELFINO, 2003).

O Código de Defesa do Consumidor é claro em seu Art. $1^{\circ}$, ao dispor que às suas normas se dirigem a proteção prioritária de um grupo social, os consumidores, e que se constituem em normas de interesse social, pois às leis de ordem pública são aquelas que interessam mais diretamente à sociedade que aos particulares, daí poderem encontrar aplicação ex officio, em especial a sanção do CDC é a nulidade taxativa absoluta (BENJAMIN; MARQUES; BESSA, 2014, p. 70).

No CDC, há a organização das normas tutelares de direito público e aplicação da função social, assim não se estabeleceu somente a defesa do consumidor como essencial, mas também a garantia de direitos concorrentes, como: a proteção da vida, saúde, segurança, educação e demais restantes, que estão previstos na normativa da lei consumerista e que são básicos e pertencentes de toda a sociedade (BRASIL, 1990).

Em vista de que os direitos individuais e sociais fossem protegidos, instituiu-se no CDC a Política Nacional das Re- 
lações de Consumo, com normas preventivas e reparatórias para se ter maior garantia de proteção, efetividade e equilíbrio nas relações de consumo (EFING, 2010). Por isso, o código é muito mais do que um corpo de normas, é um conjunto de princípios necessários e instrumentais adequados para efetivação da defesa do consumidor.

Entende-se que o CDC abrange valores e garantias fundamentais principiológicas, sendo complementar do mandamento constitucional com característica de ordem pública e de lei de função social. Desse modo, há a instituição de direitos e princípios básicos na normativa do ordenamento consumerista, os quais requerem observância obrigatória e são de grande importância para os consumidores, pois visam evitar e proteger as variadas situações inadequadas na prática de consumo.

\section{PRINCÍPIOS E DIREITOS BÁSICOS DOS CONSUMIDORES}

A entrada em vigor de uma lei de função social teve como consequência alterações relevantes perante as relações jurídicas de consumo. Por isso, para que o consumidor fosse completamente respeitado, foram designados os princípios e os direitos básicos dos consumidores no CDC. Logo, os princípios encontram-se inicialmente por meio do art. $4^{\circ}$ e dos incisos seguintes do Código, os quais visam à adequada interpretação e aplicabilidade das normas consumeristas pelos fornecedores dos produtos e dos serviços no comércio de consumo (BENJAMIN; MARQUES; BESSA, 2014).

Com efeito, Art. $4^{\circ}$ do Código de Defesa do Consumidor se constitui numa verdadeira alma, no sentido de que visa a atender não apenas às necessidades dos consumidores e respeito à sua dignidade - de sua saúde e segurança, proteção de seus interesses econômicos, melhoria de sua qualidade de vida, como também à imprescin- 
dível harmonia das relações de consumo (FILOMENO, 2014, p. 13).

Dentre os princípios que constam no art. $4^{\circ}$, pode-se citar o princípio da vulnerabilidade, o qual ressalta que os consumidores são passíveis de sofrerem injustiças por serem eles a parte mais fraca das relações de consumo (BENJAMIN; MARQUES; BESSA, 2014). Esse princípio, incide sobre qualquer sujeito, independentemente de seu grau cultural ou financeiro. A sua finalidade é contemplar situações nas quais há de fato a ausência de conhecimentos necessários sobre as atividades de fornecimentos de produtos e serviços pelos sujeitos consumidores (MIRAGEM, 2014).

O direito subjetivo do consumidor ao equilíbrio contratual constitui efeito da principiologia do direito do consumidor, muito especialmente dos princípios da boa-fé, da vulnerabilidade e, especialmente, do próprio princípio do equilíbrio. O equilíbrio contratual é antes de tudo o equilíbrio dos interesses dos contratantes, consumidor e fornecedor. Neste sentido, parece-nos desenvolver-se em um tríplice perspectiva: a) o equilíbrio econômico do contrato; b) a equiparação ou equidade informacional das partes; e c) o equilíbrio do poder na direção da relação contratual (MIRAGEM, 2014, p. 204).

Com vista à vulnerabilidade, a determinação lógica da normativa consumerista é pelo do reconhecimento dos direitos subjetivos dos consumidores (MIRAGEM, 2014). Nesse sentido, além da vulnerabilidade e dos princípios iniciais do CDC, há espécies de direitos indisponíveis nas relações de consumo, sendo eles os direitos e os princípios básicos dos consumidores que estão presentes no art. $6^{\circ}$ e nos incisos seguintes do Código:

Art. $6^{\circ}$ São direitos básicos do consumidor: 
I - a proteção da vida, saúde e segurança contra os riscos provocados por práticas no fornecimento de produtos e serviços considerados perigosos ou nocivos;

II - a educação e divulgação sobre o consumo adequado dos produtos e serviços, asseguradas a liberdade de escolha e a igualdade nas contratações;

III - a informação adequada e clara sobre os diferentes produtos e serviços, com especificação correta de quantidade, características, composição, qualidade, tributos incidentes e preço, bem como sobre os riscos que apresentem;

IV - a proteção contra a publicidade enganosa e abusiva, métodos comerciais coercitivos ou desleais, bem como contra práticas e cláusulas abusivas ou impostas no fornecimento de produtos e serviços;

V - a modificação das cláusulas contratuais que estabeleçam prestações desproporcionais ou sua revisão em razão de fatos supervenientes que as tornem excessivamente onerosas;

VI - a efetiva prevenção e reparação de danos patrimoniais e morais, individuais, coletivos e difusos;

VII - o acesso aos órgãos judiciários e administrativos com vistas à prevenção ou reparação de danos patrimoniais e morais, individuais, coletivos ou difusos, assegurada a proteção Jurídica, administrativa e técnica aos necessitados;

VIII - a facilitação da defesa de seus direitos, inclusive com a inversão do ônus da prova, a seu favor, no processo civil, quando, a critério do juiz, for verossímil a alegação ou quando for ele hipossuficiente, segundo as regras ordinárias de experiências;

IX - (Vetado);

$\mathrm{X}$ - a adequada e eficaz prestação dos serviços públicos em geral. (BRASIL, 1990).

Os direitos básicos dos consumidores são necessários para a efetivação da proteção do consumidor sob o aspecto 
de direito e garantia fundamental. Trata-se da atuação e realização de um direito fundamental de proteção do Estado para o sujeito consumidor, o qual precisou ser protegido de forma especial pela tutela dos direitos básicos no corpo do ordenamento consumerista (BENJAMIN; MARQUES; BESSA, 2014). Portanto, pela normativa do CDC, visa-se a normas com fundamentos de caráter constitucionais e obrigações que devem ser extremamente observadas pelos fornecedores diante da disponibilização de seus produtos ou serviços no mercado de consumo.

\subsection{Princípio da informação adequada e a proteção da saúde do consumidor}

Uma das maiores formas de efetivação aos direitos básicos do consumidor por parte do fornecedor desenvolve-se pela estrita observância do princípio e do direito da informação adequada. Marques, Benjamin e Miragem (2010) expõem que o direito à informação adequada assegura a igualdade material e formal entre os contratantes, pois o que define o consumidor é o seu déficit informacional sobre os produtos e serviços, suas características, qualidade, componentes e riscos, ou seja, sua vulnerabilidade.

Quanto ao texto da Lei Consumerista, estabelece o seu Art. $6^{\circ}$, inc. III, que constitui direito básico dos consumidores a informação adequada e clara sobre os diferentes produtos e serviços, com especificação correta de quantidade, características, composição, qualidade, tributos incidentes e preço, bem como sobre os riscos que apresentam (TARTUCE, 2015, p. 40).

A informação possui dois lados: o dever de informar e o de ser informado, sendo o primeiro relacionado com fornecedor do produto ou serviço e o segundo, com o consumidor vulnerável. O dever de informar atribui ao fornecedor a obrigação de 
prestar informações iniciais preparatórias e de informar sobre a composição final dos produtos e dos serviços (MARQUES; BENJAMIN; MIRAGEM, 2010). Por essa razão, é preciso que se efetive o direito de escolha, devendo essas informações serem claras e adequadas para os consumidores.

A informação deve ser clara e adequada, e esta nova transparência rege o momento pré-contratual, rege eventual conclusão do contrato, o próprio contrato e o momento pós-contratual. É mais do que um simples elemento formal, afeta a essência do negócio, pois, a informação repassada ou requerida integra o conteúdo do contrato, ou, se falha, representa falha (vício) na qualidade do produto ou serviço oferecido. (BENJAMIN; MARQUES; BESSA, 2014, p. 77).

É necessário equidade informacional entre os consumidores e os fornecedores, de forma que seja assegurada a possibilidade de acesso aos conhecimentos e às informações adequadas sobre os aspectos essenciais dos produtos ou dos serviços que irão ser adquiridos e constituirão o negócio jurídico (MIRAGEM, 2014). Equivale toda informação adequada ou publicidade transmitida aos consumidores que sejam suficientemente precisas e corretas. Com a informação adequada, os consumidores possuem o direito à livre escolha e à igualdade nas contratações perante as relações de consumo.

Além do dever de informação, vale ressaltar a proteção do consumidor no que tange à sua vida e saúde. Ao fornecedor cabe garantir que os produtos ou os serviços postos no mercado de consumo sejam seguros aos consumidores (NETTO, 2014). Para que essa segurança seja concretizada, cabe mencionar o inciso I do art. $6^{\circ}$ do $\mathrm{CDC}$, que dispõe sobre a "proteção da vida, saúde e segurança contra os riscos provocados por práticas no fornecimento de produtos e serviços considerados perigosos ou nocivos" (BRASIL, 1990). 
O inciso I do art. 6 assegura um direito de proteção "da vida, saúde e segurança", o mais básico e o mais importante dos direitos do consumidor, ainda mais tendo em vista que nossa sociedade é uma sociedade de riscos, muitos produtos, muitos serviços e mesmo práticas comerciais são efetivamente perigosos e danosos para os consumidores (BENJAMIN; MARQUES; BESSA, 2014, p. 74).

Com base no art. $6^{\circ}$ e no inciso I do CDC, todos os fornecedores têm a obrigação de respeitar e preservar, de forma especial, a vida, a saúde e a segurança dos consumidores ao disponibilizarem seus produtos ou serviços no mercado de consumo (BRASIL, 1990). Por direito à saúde, entende-se que é um direito que deve ser garantido ao consumidor no oferecimento de produtos e serviços, assim como no consumo e na utilização deles. Além disso, os produtos ou serviços devem possuir todas as condições adequadas para que ocorra a preservação da integridade física e psíquica dos consumidores (MIRAGEM, 2014).

A ideia de risco é indissociável do fornecimento de produtos e serviços, sobretudo em função das mais variadas tonalidades culturais, sociais e econômicas que envolver os consumidores. O inciso I do art. $6^{\circ}$ pretende sinalizar que os riscos não poderão comprometer a integridade física dos consumidores, seja pela proibição do comércio de produtos ou serviços de alta periculosidade, seja pela imposição de medidas protetivas - notadamente no campo das informações - hábeis a possibilitar a fruição segura dos produtos e serviços adquiridos (OLIVEIRA, 2011, p. 73).

Para que os consumidores não sejam expostos a extremos perigos e danos, é preciso haver a informação adequada sobre os riscos que os produtos ou serviços possam apresentar, ou, simplesmente, eles não devem ser colocados no mercado se, 
por acaso, os riscos forem além do que normalmente se espera. Os riscos serão sempre excessivos quando as informações disponibilizadas não puderem prevenir os acidentes e os danos nas relações de consumo (OLIVEIRA, 2011).

$\mathrm{O}$ artigo $8^{\circ}$ do CDC consignou: "os produtos e serviços colocados no mercado de consumo não acarretarão riscos à saúde ou segurança dos consumidores, exceto os considerados normais e previsíveis em decorrência de sua natureza e fruição, obrigando-se os fornecedores, em qualquer hipótese, a dar informações necessárias e adequadas a respeito" (NETTO, 2015, p. 65).

A obrigação de informar aumenta com a proporção da nocividade ou periculosidade dos produtos ou dos serviços que são ofertados no mercado de consumo. $\mathrm{O}$ art. $8^{\circ}$ do ordenamento consumerista não proíbe a comercialização de produtos e serviços que são, de certo modo, perigosos, desde que as informações prestadas pelos fornecedores na relação de consumo permitam o uso ou a fruição desses produtos ou serviços, sem acarretar danos e prejuízos (OLIVEIRA, 2011).

O fornecedor possui o dever de informar de maneira ostensiva e adequada a respeito da respectiva nocividade ou periculosidade dos produtos e dos serviços. Uma informação é ostensiva quando é transmitida de forma corretamente translúcida, ao ponto de que um consumidor, com pouca inteligência, não possa declarar a não compreensão ou desinformação. É adequada quando, de uma forma conveniente, divulgar todos os esclarecimentos e as informações necessárias para o uso e o consumo consciente dos produtos e dos serviços (GRINOVER et al, 2011).

$\mathrm{O}$ dever de esclarecimento obriga o fornecedor a detalhar da forma de utilização do produto ou da fruição do serviço, através dos manuais, bulas, livretos, enfim, tudo o mais que puder auxiliar o consumidor, sempre primo- 
rando pela utilização de termos claros e com destaque em caso de riscos à saúde ou restrição aos direitos do consumidor (SCHWARTZ, 2013, p. 70).

Os fornecedores devem retirar do mercado de consumo produtos e serviços que venham a apresentar extremos riscos à saúde e à segurança dos consumidores. A informação adequada complementa as condições dos produtos ou dos serviços e, quando insuficiente, pode ocasionar prejuízos e danos. Por isso mesmo é que os direitos básicos se relacionam entre si, pois a informação adequada é mais do que um mero conteúdo formal, ela é base para os fornecedores respeitarem também os demais direitos básicos, como o direito à vida, à saúde e à segurança dos consumidores (SCHWARTZ, 2013).

Para que ocorra a efetivação principalmente ao direito da preservação da saúde do consumidor, é necessário que os fornecedores apliquem completamente as disposições do CDC, devendo ser divulgadas informações claras e adequadas sobre os serviços e os produtos por meio das embalagens e rotulagens, sempre levando em consideração que os destinatários dessas informações não são apenas os consumidores habituais que possuem capacidade absoluta de compreensão, mas também os consumidores com pouca condição de discernimento (OLIVEIRA, 2011).

Assim, tem-se o entendimento de que os direitos básicos dos consumidores empregados como princípios são imprescindíveis para a concretização do direito do consumidor como direito e garantia fundamental. Por isso, na intenção de evitar danos aos consumidores, o CDC deu tratamento especial para esses direitos e desenvolveu obrigações aos fornecedores, os quais devem ter imperiosa cautela ao fornecerem seus produtos ou serviços no mercado de consumo, como no caso dos alimentos, que necessitam de informação adequada parente a sua rotulagem. 


\section{A FALTA DE INFORMAÇÕES ADEQUADAS NOS RÓTULOS DOS ALIMENTOS}

Para que o direito e a proteção à saúde sejam concretizados nas relações de consumo, uma rotulagem dos alimentos com informação adequada é essencial, pois é por meio do que consta nos rótulos alimentares que os consumidores obtêm a garantia da sua liberdade de escolha. Ou seja, os dados que são repassados transmitem informações das quais os consumidores podem decidir sobre o consumo. Por esse motivo, os rótulos devem expor claramente dados informativos sobre os riscos que os componentes incrementados nos alimentos podem ocasionar para a saúde dos consumidores (ESTORNINHO, 2008).

A comunicação entre o consumidor e o alimento a ser adquirido acontece pela rotulagem, a qual orienta o consumidor sobre a qualidade e a quantidade dos constituintes nutricionais do produto, de modo que as informações constantes no rótulo devam ser apresentadas em linguagem objetiva, legível e fidedigna, com o intuito de promover as escolhas alimentares apropriadas àquele consumidor (CÂMARA et al., 2008, p. 52).

A rotulagem dos alimentos deve servir como imposição para que os consumidores não sejam alvos de propagandas omissas, enganosas e indevidas. Por intermédio da sua disponibilização, há informações necessárias que devem ser passadas para que se tenha segurança no comércio e para a preservação da saúde de todos os que consomem os alimentos (ABEA, 2003). Tendo em vista a relação consumerista, é preciso analisar os possíveis riscos à saúde que a ausência de informações adequadas nos alimentos pode causar.

Outras formas de efetivação do dever de proteção do Estado se dão no direito à informação assegurada por ele, para que o indivíduo possa ter conhecimento da sua composição e assim possa escolher o que vai consumir. 
O consumo deve ser uma opção do consumidor e não uma imposição nem do Estado e nem da indústria alimentícia, para tanto se faz necessário a efetivação do acesso à informações claras e precisas, bem como a rotulagem dos alimentos que agregada à informação, permite que o consumidor saiba da origem do alimento, forma de cultivo e industrialização (JEREISSATI, 2018, p. 80).

É necessário que fabricantes de alimentos assegurem aos consumidores o acesso a informações úteis e confiáveis sobre o produto que estão adquirindo. A Agência Nacional de Vigilância Sanitária, reconhecida pela sigla ANVISA, é o principal órgão competente para determinar as informações e o modo como os rótulos devem ser postos ao mercado de consumo. Assim, os fornecedores e as empresas dos alimentos possuem a obrigação de respeitar e averiguar quais as disposições e regras são interpostas sob o aspecto da rotulagem (ANVISA, 2020).

Entretanto, a ANVISA, para sua atuação, segue legislações que disciplinam a respeito da rotulagem dos alimentos, como, por exemplo, a Resolução n ${ }^{\circ}$ 54, de 12 de novembro de 2012, que versa a respeito do Regulamento Técnico MERCOSUL sobre Informação Nutricional Complementar. Nesse Regulamento, é previsto que a declaração de propriedades nutricionais seja complementar às estratégias de política de saúde dos Estados-Partes (Argentina, Brasil, Paraguai, Uruguai, Venezuela) em benefício da saúde do consumidor, considerando requisitos importantes:

REGULAMENTO TÉCNICO MERCOSUL SOBRE INFORMAÇÃO NUTRICIONAL COMPLEMENTAR (DECLARAÇÕES DE PROPRIEDADES NUTRICIONAIS) TENDO EM VISTA:

O Tratado de Assunção, o Protocolo de Ouro Preto e as Resoluções N 38/98, 56/02, 44/03, 46/03, 47/03, 31/06 e 48/06 do Grupo Mercado Comum.

CONSIDERANDO: 
Que a informação fornecida pela declaração de propriedades nutricionais complementará as estratégias e políticas de saúde dos Estados Partes em benefício da saúde do consumidor.

Que a informação nutricional complementar facilitará o conhecimento do consumidor sobre as propriedades nutricionais dos alimentos, contribuindo para a seleção adequada dos mesmos.

Que a informação fornecida ao consumidor deve ser de fácil compreensão.

Que é necessário estabelecer requisitos que regulem a informação nutricional complementar contida nos rótulos, meios de comunicação e em toda mensagem transmitida de forma oral ou escrita sobre os alimentos que sejam comercializados prontos para a oferta ao consumidor, a fim de evitar que tal informação seja falsa, enganosa ou confusa para o consumidor.

Que é conveniente definir claramente a informação nutricional complementar que os alimentos embalados comercializados no MERCOSUL poderão conter, com o objetivo de facilitar a livre circulação dos mesmos, atuar em benefício do consumidor e evitar barreiras técnicas ao comércio (BRASIL, 2012).

Com base nas considerações presentes na Resolução $n^{\circ}$ 54, de 12 de novembro de 2012, tem-se que a Informação Nutricional Complementar (Declarações de Propriedades Nutricionais): é qualquer representação que afirme, sugira ou implique que um alimento possui propriedades nutricionais particulares, especialmente não somente em relação ao seu valor energético e/ou ao seu conteúdo de proteínas, gorduras, carboidratos e fibra alimentar, mas também quanto ao seu conteúdo de vitaminas e minerais (BRASIL, 2012). Dessa forma, na Resolução são estabelecidos quais os alimentos que precisam da Informação Nutricional Complementar (INC) presente nos rótulos dos alimentos embalados, produ- 
zidos e comercializados no território dos Estados-Partes do MERCOSUL.

Além do Regulamento mencionado, existem outras regras que a ANVISA precisa averiguar em relação aos rótulos dos alimentos, como as estabelecidas na Instrução Normativa 22, de 24 de outubro de 2005, que estabelece o Regulamento Técnico para Rotulagem de Produto de Origem Animal Embalado, o qual prevê as seguintes determinações:

\section{INFORMAÇÃO OBRIGATÓRIA}

Caso o presente Regulamento Técnico ou um regulamento técnico específico não determine algo em contrário, a rotulagem de produto de origem animal embalado deve apresentar, obrigatoriamente, as seguintes informações: - denominação (nome) de venda do produto de origem animal: o nome do produto de origem animal deve ser indicado no painel principal do rótulo em caracteres destacados, uniformes em corpo e cor, sem intercalação de desenhos e outros dizeres;

O tamanho da letra utilizada deve ser proporcional ao tamanho utilizado para a indicação da marca comercial ou logotipo caso existam; - lista de ingredientes: a lista de ingredientes deve ser indicada no rótulo em ordem decrescente de quantidade, sendo os aditivos citados com função e nome e número de INS; - conteúdos líquidos: o(s) conteúdo(s) líquido(s) devem ser indicado(s) no painel principal do rótulo de acordo com o Regulamento Técnico Específico; - identificação da origem; - nome ou razão social e endereço do estabelecimento; - nome ou razão social e endereço do importador, no caso de produtos de origem animal importado; - carimbo oficial da Inspeção Federal;

Categoria do estabelecimento, de acordo com a classificação oficial quando do registro do mesmo no DIPOA; - CNPJ; - conservação do produto; - marca comercial do produto; - identificação do lote; - data de fabricação; 
- prazo de validade; - composição do produto; - indicação da expressão: Registro no Ministério da Agricultura SIF/DIPOA sob $\mathrm{n}^{\mathrm{o}} \longrightarrow$ preparo e uso do produto de origem animal comestível ou alimento, quando necessário (BRASIL, 2005).

As regras previstas no informativo devem ser aplicadas na rotulagem de todos os produtos de origem animal que sejam designados para o comércio interestadual e internacional. Assim, conforme a origem animal caracterizada, os produtos devem ser embalados e ficar prontos para a oferta ao consumidor. Nos casos em que as características particulares de um produto de origem animal requerer uma regulamentação específica, esta deve ser sobreposta de maneira complementar ao disposto no Regulamento Técnico de Produto de Origem Animal Embalado (BRASIL, 2005).

Verifica-se que os alimentos possuem categorias e características peculiares. Por esse motivo, além desses regulamentos mencionados, há a instituição de outras ordenações que a ANVISA deve observar, podendo-se citar: Resolução RDC n ${ }^{\circ} 360$, de 23 de dezembro de 2003, Resolução RDC n ${ }^{\circ}$ 269, de 22 de setembro de 2005, (IDR) de proteína, vitaminas e minerais, Resolução RDC no 359 , de 23 de dezembro de 2003, Resolução RDC n ${ }^{\circ} 163$, de 16 de agosto de 2006, a Lei $\mathrm{n}^{\mathrm{o}}$ 8.918, de 14 de Julho de 1994, e principalmente o CDC (MACHADO, 2015, p.10).

Não obstante, a ANVISA determina que, para a rotulagem dos alimentos, é necessário que haja a lista de ingredientes, o prazo de validade, as informações nutricionais e as medidas caseiras que informam sobre as quantidades, como, por exemplo: fatias, xícaras, colheres etc. Além do mais, devem constar informações importantes sobre conservantes, lactose, glúten e diversos outros itens usados na composição do alimento, tendo em vista pessoas que possuem algum tipo de 
alergia, intolerância ou doenças, como obesidade, hipertensão e diabetes (ANVISA, 2020).

Mesmo com as regulamentações existentes, A ANVISA não faz verificação prévia de rótulos alimentares postos ao mercado de consumo. A adequação à legislação e às regras é de responsabilidade das empresas e dos fornecedores dos alimentos, sendo vedado o uso de palavras e informações falsas que induzem ao erro na rotulagem (ANVISA, 2020). Destarte, por mais que a rotulagem seja regularizada por um órgão competente e com determinações legais para serem aplicadas, nota-se que não está de acordo com o que é regrado pelo CDC, no que diz respeito às informações acerca dos riscos que o produto pode causar à saúde do consumidor.

À vista disso, a não observância da lei consumerista na hora que disponibilizar os produtos alimentícios no mercado de consumo já trouxe questionamentos e conflitos para o judiciário. Desse modo, é possível verificar nos rótulos dos alimentos a não incidência da aplicação do direito da informação adequada e o da preservação da saúde do consumidor por meio de casos que vêm sendo julgados há alguns anos pelo Superior Tribunal de Justiça (STJ), como, por exemplo:

PROCESSO CIVIL. DIREITO DO CONSUMIDOR. AÇÃO COLETIVA. DIREITO À INFORMAÇÃO. ROTULAGEM DE PRODUTOS ALIMENTÍCIOS. PRESENÇA DE GLÚTEN. PREJUÍZOS À SAÚDE DOS DOENTES CELÍACOS. INSUFICIÊNCIA DA INFORMAÇÃO-CONTEÚDO "CONTÉM GLÚTEN". NECESSIDADE DE COMPLEMENTAÇÃO COM A INFORMAÇÃO-ADVERTÊNCIA SOBRE OS RISCOS DO GLÚTEN À SAÚDE DOS DOENTES CELÍACOS. [...] O CDC traz, entre os direitos básicos do consumidor, a "informação adequada e clara sobre os diferentes produtos e serviços, com especifi- 
cação correta de quantidade, características, composição, qualidade e preço, bem como sobre os riscos que apresentam" (art. 6 ${ }^{\circ}$, inciso III). 3. Ainda de acordo com o CDC, "a oferta e a apresentação de produtos ou serviços devem assegurar informações corretas, claras, precisas, ostensivas e em língua portuguesa sobre suas características, qualidades, quantidade, composição, preço, garantia, prazos de validade e origem, entre outros dados, bem como sobre os riscos que apresentam à saúde e segurança dos consumidores" (art. 31). 6. O fornecedor de alimentos deve complementar a informação-conteúdo "contém glúten" com a informação-advertência de que o glúten é prejudicial à saúde dos consumidores com doença celíaca. Embargos de divergência providos para prevalecer a tese do acórdão paradigma no sentido de que a informação-conteúdo “contém glúten" é, por si só, insuficiente para informar os consumidores sobre o prejuízo que o alimento com glúten acarreta à saúde dos doentes celíacos, tornando-se necessária a integração com a informação-advertência correta, clara, precisa, ostensiva e em vernáculo: “CONTÉM GLÚTEN: O GLÚTEN É PREJUDICIAL À SAÚDE DOS DOENTES CELÍACOS” [...] (BRASIL, 2017, p. 2).

No respectivo caso, foi determinado que somente a informação "contém glúten" não é suficiente para informar ao consumidor sobre os danos que o consumo do glúten pode causar para a saúde, sendo necessário, por esse motivo, que conste nos rótulos que possuam alimentos com essa característica nutricional a informação de que o "glúten é prejudicial para a saúde dos celíacos". Com essa modificação na rotulagem dos alimentos, a informação se torna adequada ao ponto de garantir a segurança da saúde do consumidor.

Ainda assim, cabe destacar: 
CONSUMIDOR. VÍCIO DE QUANTIDADE. VENDA DE REFRIGERANTE EM VOLUME MENOR QUE O HABITUAL. REDUÇÃO DE CONTEÚDO INFORMADANA PARTE INFERIOR DO RÓTULO E EM LETRAS REDUZIDAS. INOBSERVÂNCIA DO DEVER DE INFORMAÇÃO. DEVER POSITIVO DO FORNECEDOR DE INFORMAR. FRUSTRAÇÃO DAS EXPECTATIVAS LEGÍTIMAS DO CONSUMIDOR. [...] 1. No caso, o Procon estadual instaurou processo administrativo contra a recorrente pela prática da infração às relações de consumo conhecida como "maquiagem de produto" e "aumento disfarçado de preços", por alterar quantitativamente o conteúdo dos refrigerantes "Coca Cola", "Fanta", "Sprite" e "Kuat" de $600 \mathrm{ml}$ para $500 \mathrm{ml}$, sem informar clara e precisamente aos consumidores, porquanto a informação foi aposta na parte inferior do rótulo e em letras reduzidas. 3. O direito à informação, garantia fundamental da pessoa humana expressa no art. $5^{\circ}$, inciso XIV, da Constituição Federal, é gênero que tem como espécie 4. A Lei n. 8.078/1990 traz, entre os direitos básicos do consumidor, a "informação adequada e clara sobre os diferentes produtos e serviços, com especificação correta de quantidade, características, composição, qualidade e preço, bem como sobre os riscos que apresentam" (art. $6^{\circ}$, inciso III). 6. O dever de informação positiva do fornecedor tem importância direta no surgimento e na manutenção da confiança por parte do consumidor. A informação deficiente frustra as legítimas expectativas do consumidor, maculando sua confiança [...] (BRASIL, 2013, p. 2).

Não é de hoje que o direito do consumidor se demonstra essencial perante os alimentos e a sua rotulagem. No caso apresentado, evidencia-se que os direitos básicos dos consumidores também não são respeitados quando a quantidade do alimento diminui e ocorre "maquiagem do produto" com uma informação falha de difícil visualização e com o "aumento 
disfarçado do preço", ou seja, o consumidor compra menos e paga mais sem perceber.

Essa conduta, entre outras constatadas perante as relações de consumo, gera a quebra de confiança na hora da aquisição do produto. Dessa maneira, havendo divergências e irregularidades em decorrência da não observância ao CDC para o desenvolvimento da rotulagem dos alimentos, ressalta-se que é preciso que ocorra alteração em sua regulamentação para que se garanta liberdade de escolha, consumo consciente, confiança e, principalmente, a preservação da saúde dos consumidores.

\subsection{Alteração da rotulagem dos alimentos para preservação da saúde do consumidor}

Todos os indivíduos de uma sociedade se proporcionam a buscar altos índices nutritivos e demais características que garantam uma vida "saudável”. Nesse sentido, é necessário asseverar a oferta e a certeza de acessibilidade a alimentos seguros e adequados, que sejam provenientes de sistemas de produção competentes e confiáveis (ANDRADE; LUZ, 2018). Todavia, com o aumento da oferta de alimentos modificados por aditivos alimentares no mercado de consumo, tornou-se difícil a efetivação de uma alimentação adequada e uma vida saudável.

O progresso científico e tecnológico trouxe mais conhecimentos sobre os benefícios e malefícios de determinados componentes alimentares, aumentando a preocupação e a conscientização das pessoas sobre a saúde e seus hábitos alimentares, os quais refletiram diretamente na rotulagem dos alimentos. Os rótulos ganharam nova função, deixando de ser apenas instrumentos de publicidade para tornarem-se, sobretudo, instrumentos de informação (ALVES; LIMA, 2018).

Os alimentos modificados e abrangidos pelos aditivos alimentares são classificados como alimentos ultraprocessados. 
Esses alimentos são desenvolvidos com o elevado acréscimo de ingredientes, como sal, gorduras, açúcar, e por outras substâncias feitas em laboratórios que alteram a cor, o aroma e, consequentemente, o sabor e o condicionamento prolongado para o consumo. Pode-se citar como exemplo de alimentos ultraprocessados os biscoitos recheados, os refrigerantes, os sorvetes, os macarrões instantâneos, entre outros, que são frequentemente consumidos (BRESSAN, 2018).

Logo, esses alimentos não são nutritivos e podem ser prejudiciais para a saúde dos consumidores, tendo-se em consideração que os aditivos alimentares e os métodos do processamento modificam a composição nutricional dos alimentos e a sua essencialidade (BRESSAN, 2018). Nessa perspectiva, o direito do consumidor está correlacionado, pois os consumidores ficam vulneráveis a obter consequências pela falta de melhores esclarecimentos sobre os aditivos alimentares e demais componentes que mantêm os alimentos embalados e armazenados por um longo período.

Com a modificação dos alimentos, é preciso repassar de maneira eficiente as informações sobre os riscos que as substâncias alimentares apresentam. Em vista disso, há a necessidade de uma conveniente rotulagem que seja eficaz e ostensiva e, principalmente, que esteja de acordo com as regras do CDC. Os fornecedores devem transmitir dados de grande notoriedade para atender à necessidade e aos interesses dos consumidores. Assim, os consumidores adquirem um discernimento completo sobre os alimentos e seus riscos e as consequências que a sua composição pode causar à saúde (ALVES; LIMA, 2018).

Um dos princípios fundamentais sobre os quais se sustenta um Estado democrático é o da liberdade individual. Para o exercício dessa liberdade, é necessário que aquele que vai tomar a decisão sobre como agir possa 
orientar sua ação de forma consciente. Somente se chega a uma plena consciência sobre todas as circunstâncias relevantes que envolverão os fatos sobre os quais se terá de decidir por meio da informação (FREITAS FILHO, 2003, p. 147).

À luz da saúde dos consumidores, para que haja a alteração da rotulagem dos alimentos, foi proposto, no Plenário do Senado Federal, em 02/04/2019, o Projeto de Lei n ${ }^{\circ}$ 2313/2019, de autoria do Senador Jorge Kajuru. A proposta ainda está em tramitação e possui como base o grande déficit informacional dos consumidores e a falta de claridade no repasse de informações nos rótulos dos alimentos. "O modelo de rotulagem nutricional utilizado no Brasil não cumpre sua finalidade. As informações apresentadas são de difícil compreensão, além de estarem localizadas na parte de trás da embalagem, praticamente escondidas do consumidor" (BRASIL, 2019b).

Vem à análise da Comissão de Assuntos Sociais (CAS), o Projeto de Lei (PL) no 2.313, de 2019, de autoria do Senador Jorge Kajuru, que modifica o Decreto-Lei $\mathrm{n}^{\circ}$ 986, de 21 de outubro de 1969, que institui normas básicas sobre alimentos, para dispor sobre a rotulagem de alimentos embalados que contenham teores elevados de açúcares, sódio e gorduras. $\mathrm{O}$ art. $1^{\circ}$ da proposição acrescenta um art. 11-A à referida norma para obrigar a exibição de alertas, nos rótulos dos alimentos embalados na ausência do consumidor, sobre a presença de: (i) adoçantes e gordura trans, em qualquer quantidade; e (ii) teores elevados de açúcares, sódio e gorduras, bem como de outros nutrientes considerados pouco saudáveis (BRASIL, 2019a, p. 1).

Além disso, visando-se também à alteração da rotulagem dos alimentos, o Instituto Brasileiro de Defesa do Consumidor e os pesquisadores da Universidade Federal do Paraná apresen- 
taram para a ANVISA uma proposta de inovação com um novo formato de rotulagem dos alimentos, a fim de que conste na parte frontal das embalagens selos como forma de advertência, dispondo sobre as seguintes características: formato triangular, bordas que sejam arredondadas, com cor preta em fundo branco, texto destacado e principalmente a posição de palavras de fácil entendimento pelos sujeitos consumidores (BRASIL, 2019b).

Logo, o Projeto de Lei n 2313/2019 possui a mesma lógica da proposta do Instituto Brasileiro de Defesa do Consumidor e dos pesquisadores da Universidade Federal do Paraná, pois propõe que os alertas deverão ser feitos com mensagens de advertência na parte frontal das embalagens dos alimentos, efetuadas de forma clara, destacada, legível e de fácil esclarecimento. Tudo isso para indicar a presença de quantidades excedentes de açúcar, gorduras totais, gorduras saturadas e sódio, além de qualquer outra quantidade de adoçantes e ou de gordura trans presentes (BRASIL, 2019b).

A rotulagem nutricional deve esclarecer o consumidor acerca das propriedades nutricionais do alimento, de forma a possibilitar escolhas alimentares saudáveis. No entanto, o atual modelo utilizado no Brasil não cumpre essa finalidade, o que também contraria o Código de Defesa do Consumidor. Por esse motivo, alternativas têm sido discutidas pela Agência Nacional de Vigilância Sanitária (ANVISA), tal como a apresentada pelo Instituto Brasileiro de Defesa do Consumidor (IDEC), em conjunto com pesquisadores da Universidade Federal do Paraná, que utiliza selos de advertência. A proposta sob análise segue justamente essa linha (BRASIL, 2019b. p. 3).

Com a proposta de alteração do modelo de rotulagem dos alimentos no Projeto de Lei $n^{\circ} 2313 / 2019$, percebe-se a necessidade de mudança para que seja efetivado de fato o que é previsto no CDC. A informação adequada não é cumprida quando 
os rótulos dos alimentos reduzem e não estabelecem quais são as consequências pelo uso do produto alimentício. Assim, os alimentos colocados no mercado de consumo não podem acarretar riscos à saúde ou à segurança dos consumidores, exceto os considerados previsíveis em razão de sua natureza e fruição (SILVA; CACHAPUZ, 2007).

Uma rotulagem adequada é fonte essencial de informação para os consumidores. Informações adequadas transmitem de maneira eficaz os diferentes produtos e serviços, apresentando especificações necessárias e corretas sobre quantidade, características, composição, qualidade, tributos incidentes, preço, bem como sobre os riscos que o produto ou o serviço podem causar à saúde do consumidor, sendo esta especificação a primordial informação que não consta nas atuais rotulagens dos alimentos postos no mercado de consumo.

A simples apresentação de informações técnicas não produz efeito para compreensão do consumidor no momento de aquisição do produto. Ou seja, as informações que constam nos rótulos alimentares não possuem um significado claro (FREITAS FILHO, 2003). Os consumidores precisam ter seus direitos respeitados pelos fornecedores, os quais devem prezar pelo repasse da informação adequada nas rotulagens dos alimentos, especificando a origem e a modificação dos alimentos de maneira clara e eficaz no momento de aquisição do produto.

Os alimentos interferem na saúde dos consumidores, por isso a informação estabelecida de maneira adequada nos rótulos alimentares efetiva os demais direitos básicos dos consumidores, principalmente o da preservação da saúde (CÂMARA et al., 2008). Portanto, com um modelo de rotulagem que acompanhasse as disposições do CDC em face dos direitos básicos dos consumidores, como o da informação adequada e o da preservação à saúde, haveria mais segurança e 
discernimento para os consumidores adquirirem e usufruírem os alimentos postos no mercado de consumo.

\section{CONCLUSÃO}

No presente artigo científico, elencou-se que o direito do consumidor foi abrangido como direito fundamental na Constituição Federal de 1988. Com grande proporção na prática, instituiu-se o CDC, Lei no 8.078/1990, pelo qual se destacou a proteção da defesa do consumidor de forma mais elevada. Diante do ordenamento consumerista, teve-se a instituição da Política Nacional das Relações de Consumo e dos instrumentos hábeis para o efetivo exercício do equilíbrio e da harmonia entre os sujeitos partes das relações, ou seja, entre consumidores e fornecedores.

Analisou-se a extrema necessidade de proteção e garantia de efetividade dos direitos básicos dos consumidores, os quais foram empregados como princípios por serem imprescindíveis para a concretização da defesa do consumidor como um direito de caráter constitucional. Sendo o direito do consumidor direito fundamental constitucionalmente protegido, assim como a sua saúde, foi necessário estudar a rotulagem dos alimentos, as regras que incidem sobre ela e a proteção do consumidor nessa temática.

Verificou-se a existência de regulamentações acerca da rotulagem dos alimentos e que a ANVISA é o órgão competente para sua instituição. Os fornecedores dos produtos alimentícios devem seguir o que as regulamentações e a ANVISA dispõem. Todavia, foi averiguado que as estipulações acerca dos rótulos alimentares não estão de acordo com o que está previsto no $\mathrm{CDC}$ em relação à preservação da saúde e à informação adequada. Assim, por mais que conste que a informação seja necessária, ela ainda não é suficiente para a compreensão e a efetivação dos direitos básicos dos consumidores. 
Foram apresentados casos que foram julgados pelo Superior Tribunal de Justiça (STJ) na esfera do direito do consumidor, diante dos quais se constatou, de fato, a não observância e a não aplicação dos direitos básicos do CDC. Os casos demonstraram que a falta de informações gera problemas para os consumidores, por isso houve a necessidade da especificação "contém glúten" e que o "glúten é prejudicial para a saúde dos celíacos", como também foi preciso a proibição do aumento disfarçado do preço com a diminuição do produto para que os consumidores não sejam prejudicados.

Os conflitos expostos sob a temática da falta de informações na rotulagem dos alimentos são apenas dois exemplos de quais espécies de complicações podem os consumidores se deparar na relação de consumo, pois os problemas e os prejuízos podem ser diversos quanto aos rótulos alimentares. Porém, havendo conflitos, provou-se que a rotulagem precisa ser melhorada, tendo em vista que a informação adequada e, principalmente, a preservação da saúde sejam dois direitos básicos priorizados na perspectiva dos alimentos e a sua rotulagem.

Por esse aspecto, foi elencada a apresentação do Projeto de Lei $\mathrm{n}^{\mathrm{o}} 2313 / 2019$, que visa a alteração da rotulagem dos alimentos, tendo-se em consideração a falta de informações para os consumidores e a falta de claridade no seu transpasse. Logo, a necessidade de um modelo de rotulagem nutricional foi abrangida com vista na pesquisa feita pela Universidade Federal do Paraná apresentada para ANVISA, propondo uma rotulagem com características melhores e de fácil entendimento na hora da aquisição e do consumo dos alimentos.

Com os conflitos e a proposta de alteração para o modelo de rotulagem dos alimentos, observou-se a estrita necessidade da obrigação para os fornecedores de disponibilizar informações adequadas nos rótulos alimentares para que os consumidores não tenham prejuízos à saúde e à insegurança nas relações de 
consumo. Nesse sentido, por não proporcionar todas as informações suficientes e precisas para que haja um consumo consciente, os rótulos alimentares não atendem aos direitos básicos e fundamentais dos consumidores.

Concluiu-se, com o que foi apresentado, que a falta de informações aquedadas nos rótulos dos alimentos é um problema atual e existente, uma vez que os consumidores vulneráveis não sabem quais as consequências do consumo das substâncias colocadas nos alimentos para a comercialização. Por isso, a rotulagem com uma informação adequada é um meio indispensável para que se efetive a preservação à vida, à segurança e, principalmente, à saúde dos consumidores. Ao encontrar informações adequadas nas rotulagens dos alimentos, os fornecedores podem evitar conflitos, riscos e danos e garantir a efetividade das disposições jurídicas do CDC nas relações de consumo.

\section{REFERÊNCIAS}

ABEA. Código de Defesa do consumidor: direcionado ao segmento alimentício. 1. ed. São Paulo: ABEA, 2003.

ALVES, Mariana Domingues; LIMA, Cintia Rosa Pereira de. O direito consumerista como instrumento para uma rotulagem de alimentos. In: FOOD LAW: UM DIÁLOGO INTERDISCIPLINAR, 2018, Ribeirão Preto. Anais eletrônicos [...]. Ribeirão Preto: FDRP-USP, 2018. Disponível em: http://www.direitorp.usp.br/wp-content/ uploads/2018/10/FOOD-LAW_-Anais_Vers\%C3\%A3oFinal.pdf. Acesso em: 6 maio 2020.

ANDRADE, Daniella Gimenes; LUZ, Cícero Krupp. A insegurança alimentar no Brasil devido aos riscos do uso abusivo de agrotóxicos: uma análise a partir do direito humano à alimentação adequada. In: FOOD LAW: UM DIÁLOGO INTERDISCIPLINAR, 2018, Ribeirão Preto. Anais eletrônicos [...]. Ribeirão Preto: FDRP-USP, 2018. Disponível em: http://www.direitorp.usp.br/wp-content/ uploads/2018/10/FOOD-LAW_-Anais_Vers\%C3\%A3oFinal.pdf. Acesso em: 14 maio 2020. 
ANVISA. Rotulagem de alimentos. Brasília, DF: Anvisa, 2020. Disponível em: http://portal.anvisa.gov.br/rotulagem-de-alimentos. Acesso em: 06 maio 2020.

BENJAMIN, Antônio Herman V; MARQUES, Claudia Lima; BESSA, Leonardo Roscoe. Manual de Direito do Consumidor. 6. ed. São Paulo: Revista dos Tribunais, 2014.

BRASIL. Lei $n^{0}$ 8.078, de 11 de setembro de 1990. Dispõe sobre a proteção do consumidor e dá outras providências. Brasília, DF: Presidência da República, 1990. Disponível em: http://www.planalto.gov.br/ ccivil_03/LEIS/L8078.htm. Acesso em: 6 maio 2020.

BRASIL. Ministério da Agricultura, Pecuária e Abastecimento. Instrução Normativa 22, de 24 de outubro de 2005, para Produtos de Origem Animal Embalado. Brasília, DF: Ministério da Agricultura, Pecuária e Abastecimento, 2005. Disponível em: http://www.cidasc. sc.gov.br/inspecao/files/2012/08/instru\%C3\%A7\%C3\%A3o-normativa-22_2005.pdf. Acesso em: 6 ago. 2020.

BRASIL. Ministério da Saúde. Resolução no 54, de 12 de novembro de 2012. Brasília, DF: Ministério da Saúde, 2012. Disponível em: http://bvsms.saude.gov.br/bvs/saudelegis/anvisa/2012/ rdc0054_12_11_2012.html. Acesso em: 6 ago. 2020.

BRASIL. Senado Federal. Parecer n.15, de 2019. Brasília, DF: Senado Federal, 2019a. Disponível em: https://legis.senado.leg.br/sdleg-getter/ documento? $\mathrm{dm}=7959679 \&$ disposition=inline\#Emenda1. Acesso em: 22 jul. 2020.

BRASIL. Senado Federal. Projeto de Lei n. 2313, de 2019. Brasília, DF: Senado Federal, 2019b. Disponível em: https://legis.senado.leg.br/ sdleg-getter/documento?dm=7941672\&ts $=1567528569368 \&$ disposition=inline. Acesso em: 22 jul. 2020.

BRASIL. Superior Tribunal de Justiça. Recurso Especial $\mathbf{N}^{\mathbf{0}}$ 1.364.915 - MG (2013/0021637-0) Relator: Min. Humberto Martins. 14 de maio 2013. Disponível em: https://ww2.stj.jus.br/processo/revista/documento/mediado/?componente $=$ ITA\&sequencial $=1232887 \&$ num_registro $=201300216370 \&$ data $=20130524 \&$ formato=PDF. Acesso em: 23 jul. 2020.

BRASIL. Superior Tribunal de Justiça, Embargos de Divergência Em Resp No 1.515.895 - MS (2015/0035424-0). Relator: Min. Humberto 
Martins. 20 de setembro de 2017. Disponível em: https://ww2.stj.jus. $\mathrm{br} / \mathrm{processo} / \mathrm{revista} /$ documento/mediado/?componente=ITA\&sequencial $=1636681 \&$ num_registro $=201500354240 \&$ data $=20170927 \&$ formato=PDF. Acesso em: 20 jul. 2020.

BRESSAN, Renata. Alimentos processados e ultraprocessados. In: ASSOCIAÇÃO BRASILEIRA PARA O ESTUDO DA OBESIDADE E SÍNDROME METABÓLICA, São Paulo, 05 nov. 2018. Disponível em: http://www.abeso.org.br/dica/alimentos-processados-e-ultraprocessados. Acesso em: 12 maio 2020.

CÂMARA, Maria Clara Coelho et al. A produção acadêmica sobre a rotulagem de alimentos no Brasil. Revista Panamericana de Salud Pública, n. 23, p. 52 - 58. 2008.

DELFINO, Lúcio. Reflexões acerca do Art. $1^{\circ}$ do Código de Defesa do Consumidor. Revista do Direito do Consumidor, v. 48, p. 161-195, dez. 2003.

EFING, Antônio Carlos. Direito do Consumo. 1. ed. Curitiba: Juruá, 2010 .

ESTORNINHO, Maria João. Segurança alimentar e protecção do consumidor de organismos geneticamente modificados. Coimbra: Ed. Almedina, 2008.

FILOMENO, José Geraldo Brito. Manual de direitos do consumidor. 12. ed. São Paulo: Atlas, 2014.

FREITAS FILHO, Roberto. Os alimentos geneticamente modificados e o direito do consumidor à informação: Uma questão de cidadania. Revista de Informação Legislativa. Brasília, n. 158, p. 143-161, abr./ jun. 2003. Disponível em: https://www2.senado.leg.br/bdsf/bitstream/ handle/id/496890/RIL158.pdf? sequence=1\#page=140. Acesso em: 12 maio 2020.

GRINOVER, Ada Pellegrini et al. Código brasileiro de defesa do consumidor: comentado pelos autores do anteprojeto. 10. ed. rev., atual. e reform. Rio de Janeiro: Forense, 2011.

JEREISSATI, Catherine Santa Cruz. Acesso à informação pelo consumidor de alimentos que contenham organismos geneticamente modificados. 2018. Dissertação (Mestrado em Direito Constitucional) - Universidade de Fortaleza, Fortaleza, 2018. 
MACHADO, Roberto Luiz Pires. Manual de rotulagem de alimentos. Rio de Janeiro: EMPRAPA, 2015. Disponível em: https://ainfo. cnptia.embrapa.br/digital/bitstream/item/142308/1/DOC-119.pdf. Acesso em: 6 ago. 2020.

MARQUES, Cláudia Lima; BENJAMIN, Antônio Herman V; MIRAGEM, Bruno. Comentários ao Código de Defesa do consumidor. 3. ed. São Paulo: Revista dos Tribunais, 2010.

MIRAGEM, Bruno. Curso de direito do consumidor. 5. ed. São Paulo: Revista dos Tribunais, 2014.

NETTO, Felipe Peixoto Braga. Manual de direito do consumidor. 10. ed., Salvador: Edições Juspodivm, 2014.

OLIVEIRA, James Eduardo. Código de defesa do consumidor. 5. ed. São Paulo: Atlas, 2011.

SCHWARTZ, Fábio. Direito do Consumidor: tópicos e controvérsias. 1. ed. Niterói; Rio de Janeiro: Impetus, 2013.

SILVA, Gilson Hugo Rodrigo; CACHAPUZ, Rozane da Rosa. A rotulagem dos alimentos transgênicos - direito do consumidor e aspecto fundamental da personalidade. Revista Jurídica Cesumar, Maringá, v. 7, n. 1, p. 119-136, jun. 2007. Disponível em: http://periodicos.unicesumar.edu.br/index.php/revjuridica/article/viewFile/519/377. Acesso em: 6 maio 2020.

TARTUCE, Flávio; NEVES, Daniel Amorim Assumpção. Manual de direito do consumidor: direito material e processual. 4. ed., rev. atual e ampl. São Paulo: Método, 2015.

Recebido em: 29/05/2020

Aprovado em: 19/07/2020 